\title{
ENHANCING THE PROPERTIES OF CONCRETE USING ELECTROMAGNETIC WATER
}

\author{
Shriprasad Chavan ${ }^{1}$, Akshata Thosare ${ }^{2}$, Priyanka Pophale ${ }^{3}$, Anuja Patil ${ }^{4}$, Abhilash Sarde ${ }^{5}$ \\ ${ }^{1}$ B.E. Student, Department of Civil Engineering, RMD Sinhgad School of Engineering, Maharashtra, India \\ ${ }^{2}$ B.E. Student, Department of Civil Engineering, RMD Sinhgad School of Engineering, Maharashtra, India \\ ${ }^{3}$ B.E. Student, Department of Civil Engineering, RMD Sinhgad School of Engineering, Maharashtra, India \\ ${ }^{4}$ B.E. Student, Department of Civil Engineering, RMD Sinhgad School of Engineering, Maharashtra, India \\ ${ }^{5}$ B.E. Student, Department of Civil Engineering, RMD Sinhgad School of Engineering, Maharashtra, India
}

\begin{abstract}
Electromagnetising of water and using it in various field is not a new concept. It has been done in agriculture, dairy, health care industries etc. But in the past few years owing to unpredictable rainfall there is a serious shortage of water. Also about $75 \%$ of the water available is hard water. Because of unavailability of water for construction practices, there is a serious need to use alternative water resources. This paper investigates whether different sources of water other than potable water can be used for construction works. Concrete mix for bore well water as well as electromagnetised bore well water were prepared and an another set of concrete mix of same proportion were prepared of the water flowing out of the STP and the electromagnetic water flowing out of the STP. Compressive strength tests conducted on the electromagnetic samples were very encouraging and can be used for replacing potable water.
\end{abstract}

Keywords: ElectroMagnetic Water1, Compressive Strenght2, Sewage Water3, and Concrete4 etc... $* * *$

\section{INTRODUCTION}

Concrete is made up of three basic components: water, aggregate (rock, sand, or gravel) and Portland cement. Cement, usually used in powered form, acts as a binding agent when mixed with water and aggregates. This combination, or concrete mix, will be poured and hardened into the durable material which we all are familiar with. The water used in this concrete mix plays a very important role in increasing the workability and the strength parameters of the concrete mix. Electromagnetic water is the water that results when passed through a electromagnetic field [1]. When the water passes through a certain electromagnetic field it becomes electromagnetic water. It is found that an increase of about $10 \%$ in strength and a reduction of about $5 \%$ in cement dosage can be achieved [2] when the water is electromagnetised it does not change any of its mechanical properties it only changes the trajectory of the charged particles movement[2]

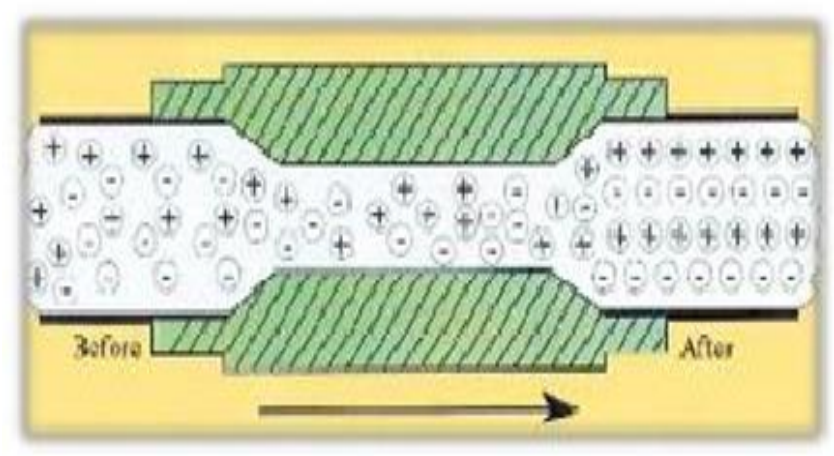

\subsection{Electromagnetic Device}



The ElectroMagnetic Device creates strong sweeping frequency magnetic field on the pipe line which carries the water flow. It consists of two components: Electronic Water Conditioner and Magnetic Water Conditioner. The Electronic Water Conditioner uses a series of controlled complex modulating high frequency waveform. This field effectively agitates different size molecules likely to form scale and to break the bonds between molecules and water. The Magnetic Water Conditioner consists of one or more permanent magnets affixed either to interior or exterior of the pipe carrying water. The two components are joined to a terminal and this terminal is then connected to a power supply. 


\subsection{Electromagnetic Water (Mechanism)}

The ElectroMagnetic Machine is properly set up and is connected to a power source. The water is allowed to pass through the machine at a flow rate of about $200 \mathrm{ml} / \mathrm{min}$. The water is made to pass through the machine at this rate for at least three times in succession. This ensures complete electromagnetising of the water. A small pump is used for the circulation of water through the machine. Hence the water coming out of the machine by following the above procedure is electromagnetised and is used in the concrete mix and also for curing purpose.

\section{EXPERIMENTAL DETAILS}

\subsection{Materials Required}

\subsubsection{Cement}

The cement used in this experimental work is Ordinary Portland Cement (Bharathi cement, 53 grade). All properties of cement are tested using I.S. specifications for OPC.

Table - 1: Physical properties of cement.

\begin{tabular}{|l|l|}
\hline Properties & Cement \\
\hline Fineness & $2.433 \%$ \\
\hline Initial Setting Time & $135 \mathrm{~min}$ \\
\hline Final Setting Time & $245 \mathrm{~min}$ \\
\hline Normal Consistency & $35 \%$ \\
\hline Specific Gravity & 3.07 \\
\hline
\end{tabular}

\subsubsection{Fine Aggregate}

The fine aggregate used was river sand confirming to zone 1 and maximum size was $4.75 \mathrm{~mm}$. The testing of sand was done as per Indian Standard Specifications IS:383-1970

\subsubsection{Coarse Aggregate}

Two types of aggregates was used for this investigation viz. $12 \mathrm{~mm}$ and $20 \mathrm{~mm}$.Sieve analysis was performed according to IS 383:1970-specification for C.A. and F.A. and IS 2386:1977-Methods of tests for aggregate of concrete.

\subsubsection{Water}

The ElectroMagnetic Water prepared by passing through the ElectroMagnetic Device is used in the concrete mix and also for curing purposes. Also Water from Bore well and sewage water flowing out of a STP is used. Water cement ratio of 0.5 was adopted for this study.

\subsubsection{GGBS (Ground Granulated Blast Furnace} Slag)

The main components of blast furnace slag are $\mathrm{CaO}$ (30$50 \%), \mathrm{SiO} 2(28-38 \%), \mathrm{Al} 2 \mathrm{O} 3(8-24 \%)$, and $\mathrm{MgO}$ (1$18 \%$ ). The GGBS of JSW cement was used. It is off-white colour and substantially lighter than Portland cement. The advantage of GGBS when used with Portland cement ensures higher durability of concrete avoids thermal cracking and improves workability. $50 \%$ by weight of cement was replaced by GGBS.

\subsubsection{Mix Design}

The present investigation on M20 grade of concrete mix trials were done on procured material. The Indian Standard Mix Design procedure is adopted (i.e. IS: 10262-2009) to arrive at mix proportions of M20 grade. The detailed mix design of M2o grade of concrete is given in Table 2.

Table-2: Trial Mix Proportion for $1 \mathrm{~m} 3$ of concrete

\begin{tabular}{|l|l|}
\hline Material & Quantity in KG \\
\hline Cement & 310 \\
\hline Sand & 719 \\
\hline 20mm Aggregate & 700 \\
\hline 12mm Aggregate & 466 \\
\hline Water & 170.5 \\
\hline
\end{tabular}

\subsection{Methodology}

The property of cement, aggregate, water is obtained by using standard IS methods and obtained values are considered.

A compressive test of different samples is done for 7,14 and 28 days respectively. Compressive strength is measured by a compressive testing machine. The compressive strength is the average of the three samples for each percentage.

\subsubsection{Preparation of Test Samples}

Concrete cubes of size $150 \mathrm{mmX} 150 \mathrm{mmX} 150 \mathrm{~mm}$ are first cast from the bore well water which is available. Alongside some of the bore well water is electromagnetised and corresponding cubes are made from this water. A total of 6 cubes are cast; 3 from bore well water and 3 from electromagnetised bore well water. After this comparison another set of 6 cubes is made; 3 cubes from the sewage water flowing out of a Sewage Treatment Plant (STP) and another three by Electromagnetising this water. The cubes are then tested for compressive strength and results are compiled.

\subsection{Compressive Test}

A cube compression test was performed on standard cubes 4 different samples of size $150 \mathrm{~mm} \times 150 \mathrm{~mm} \times 150 \mathrm{~mm}$ at 7 , 14 and 28 days of immersion in water for curing.

The compressive strength of each type of specimen is carried out for at least three times for 7, 14 and 28 days respectively. Then by taking the average of the three the final compressive strength for the specimen can be determined.

The Compressive strength of the specimen was calculated by using the formula:

$\mathrm{fck}=\mathrm{Pc} / \mathrm{A}$ 
where,

$\mathrm{Pc}=$ Failure load in compression, in $\mathrm{KN}$

$\mathrm{A}=$ Loaded area of the specimen, in $\mathrm{mm} 2$ For Coarse aggregate:

\section{RESULTS AND DISCUSSIONS}

1. When the compressive strength of the cubes made from bore well water and electromagnetic bore well water is observed it can be clearly seen that there is an increase in the strength parameter when the water is passed through the electromagnetic machine. The following graph will explain it better.

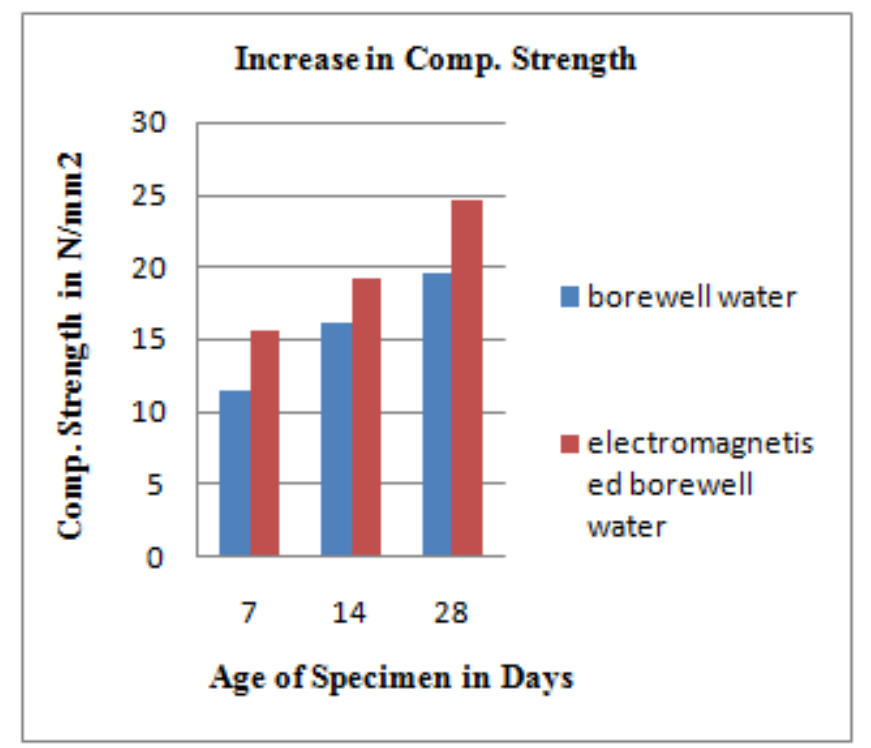

Graph-1: Increase in compressive strength by Electromagnetic Bore well Water

The graph clearly indicates that the strength of the cubes increased when the electromagnetic borewell water was used in comparison to the naturally available water. Table no. 3 gives the percentage increase in strength

Table- 3: Percentage Increase in Strength

\begin{tabular}{|l|l|l|l|}
\hline $\begin{array}{l}\text { No. of } \\
\text { Days }\end{array}$ & $\begin{array}{l}\text { Bore well } \\
\text { Water }\end{array}$ & $\begin{array}{l}\text { ElectroMagntic } \\
\text { Bore well water }\end{array}$ & $\begin{array}{l}\text { Percentage } \\
\text { Increase }\end{array}$ \\
\hline 7 & 11.3 & 15.54 & $38 \%$ \\
\hline 14 & 16.17 & 19.17 & $19 \%$ \\
\hline 28 & 19.51 & 24.51 & $26 \%$ \\
\hline
\end{tabular}

2. After the first part is done, the sewage water flowing out of the STP is used to cast cubes and this water is again electromagnatised to cast another set of cubes. These cubes are compared for compressive strength and the results are observed. The following graph shows the comparison of the results.

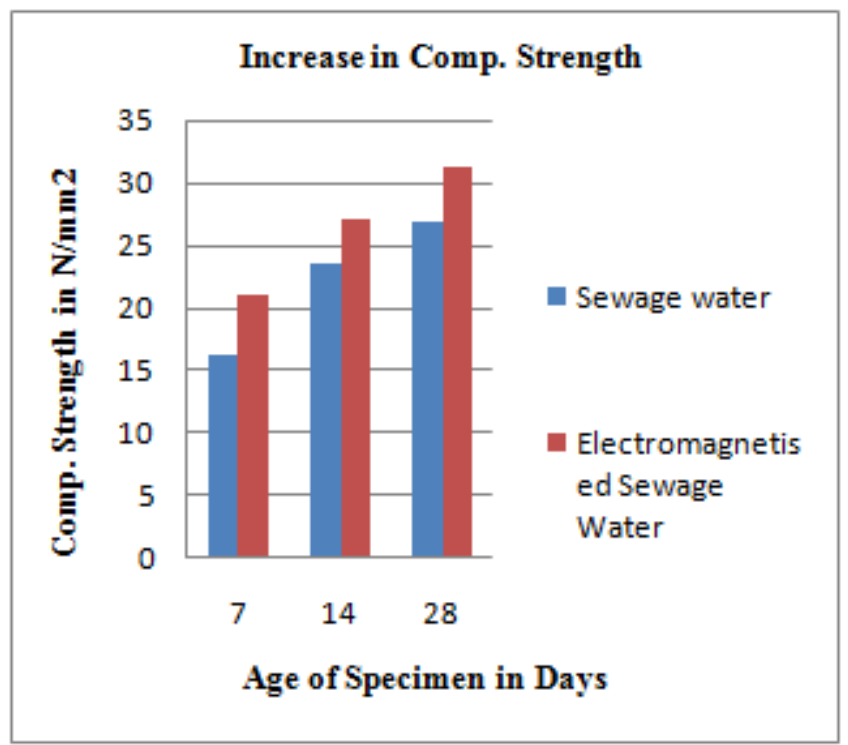

Graph-2: Increase in compressive strength by Electromagnetic Treated Sewage water

The graph shows that there is an increase in strength for 7 , 14, 28 days respectively. Therefore the water flowing out from the STP can be used for construction practices by using this technology. Table no. 4 gives the percentage increase in strength

Table-4: Percentage Increase in Strength

\begin{tabular}{|l|l|l|l|}
\hline $\begin{array}{l}\text { No. } \\
\text { of } \\
\text { Days }\end{array}$ & $\begin{array}{l}\text { Treated } \\
\text { STP water }\end{array}$ & $\begin{array}{l}\text { ElectroMagntic } \\
\text { Treated STP } \\
\text { water }\end{array}$ & $\begin{array}{l}\text { Percentage } \\
\text { Increase }\end{array}$ \\
\hline 7 & 16.08 & 21.05 & $31 \%$ \\
\hline 14 & 23.4 & 27.05 & $16 \%$ \\
\hline 28 & 26.75 & 31.24 & $17 \%$ \\
\hline
\end{tabular}

\section{APPLICATIONS}

1. All the builders and RCC manufactures can use this as it reduces a large amount of cement and water to be used.

2. It can be used in Fly ash bricks and paver blocks manufacture.

3. Cement pipe/sheets/slab manufacture.

4. All flyovers and bridge site.

5. Basically can be used anywhere where cement is used with water.

\section{ADVANTAGES}

ElectroMagnetic Device does the same thing which other chemicals do to increase the concrete properties but with a difference as below:

1. It treats water physically not chemically.

2. It increases solubility of water a must factor.

3. Treated water surface tension will be low. 
4. The salt particles get locked and can't participate in reaction.

5. No use of recurring chemicals or salts or filters.

6. One time investment for lifetime operation.

7. Fully Automatic operation, no manual interference.

8. The device can be dismantled and transported from one site to another.

\section{DISADVANTAGES}

1. It requires power supply.

2. It requires initial investment cost.

\section{CONCLUSIONS}

Thus from the experimental work the following things can be concluded:

1. Electromagnetic water can be used in construction if there is shortage of water.

2. It increases the strength of concrete so it can help in reducing the dosage of cement.

3. It increases the workability which helps in reducing the use of water.

4. It also helps in preventing the scaling caused by salts and minerals.

\section{ACKNOWLEDGEMENT}

Our sincere thanks to our guide Mr. Dashrath Mittapalli for guiding us in this study. We would also like to thank Mr. Girish Chandane and Autofill Systems for their valuable time and guidance and for providing us the ElectroMagnetic Machine. We would also like to thank Mr. Yusuf Inamdar and J Kumar Infratech Pvt. Ltd for sponsoring our project and supporting us.

\section{REFERENCES}

[1]. Nan Su; Yeong-Hwa: and Wu: and Chung-Yo 2000. Effect of magnetic water on engineering properties of concrete containing granulated blast furnace slag. Cement and Concrete Research, Department of Construction. National Yunlin University of Science and technology Section 3,123 University Road, Touliu 640, Taiwan.

[2]. Nan Su; Chea-Fang Wu 2002. Effect of magnetic field treated water on mortar and concrete containing fly ash. Cement and Concrete Research, Department of construction .National Yunlin University of Science and Technology Section 3. 123University road. Touliu 640, Taiwan.

[3]. Pang, X.F. and B. Deng (2008), "Investigation of changes in properties of water under the action of a magnetic field". Science in china series. GPhysics Mechanics Astron. 51:1621-1632

\section{BIOGRAPHIES}

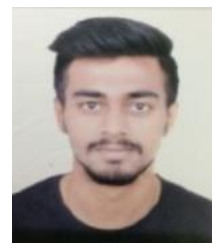

Shriprasad S. Chavan

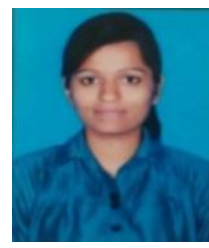

Akshata P. Thosare

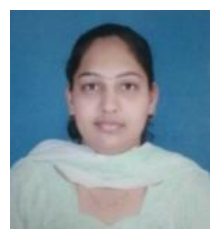

Priyanka R. Pophale

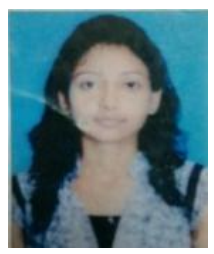

Anuja N. Patil

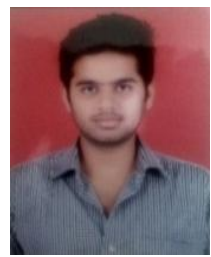

Abhilash S. Sarde 